Purdue University

Purdue e-Pubs

2010

\title{
Marangoni Convection and Thin-film Evaporation in Microstructured Wicks for Heat Pipes
}

R. Ranjan

J. Y. Murthy

S V. Garimella

Purdue University, sureshg@purdue.edu

Follow this and additional works at: http://docs.lib.purdue.edu/coolingpubs

Ranjan, R.; Murthy, J. Y.; and Garimella, S V., "Marangoni Convection and Thin-film Evaporation in Microstructured Wicks for Heat Pipes" (2010). CTRC Research Publications. Paper 252.

http://docs.lib.purdue.edu/coolingpubs/252

This document has been made available through Purdue e-Pubs, a service of the Purdue University Libraries. Please contact epubs@purdue.edu for additional information. 

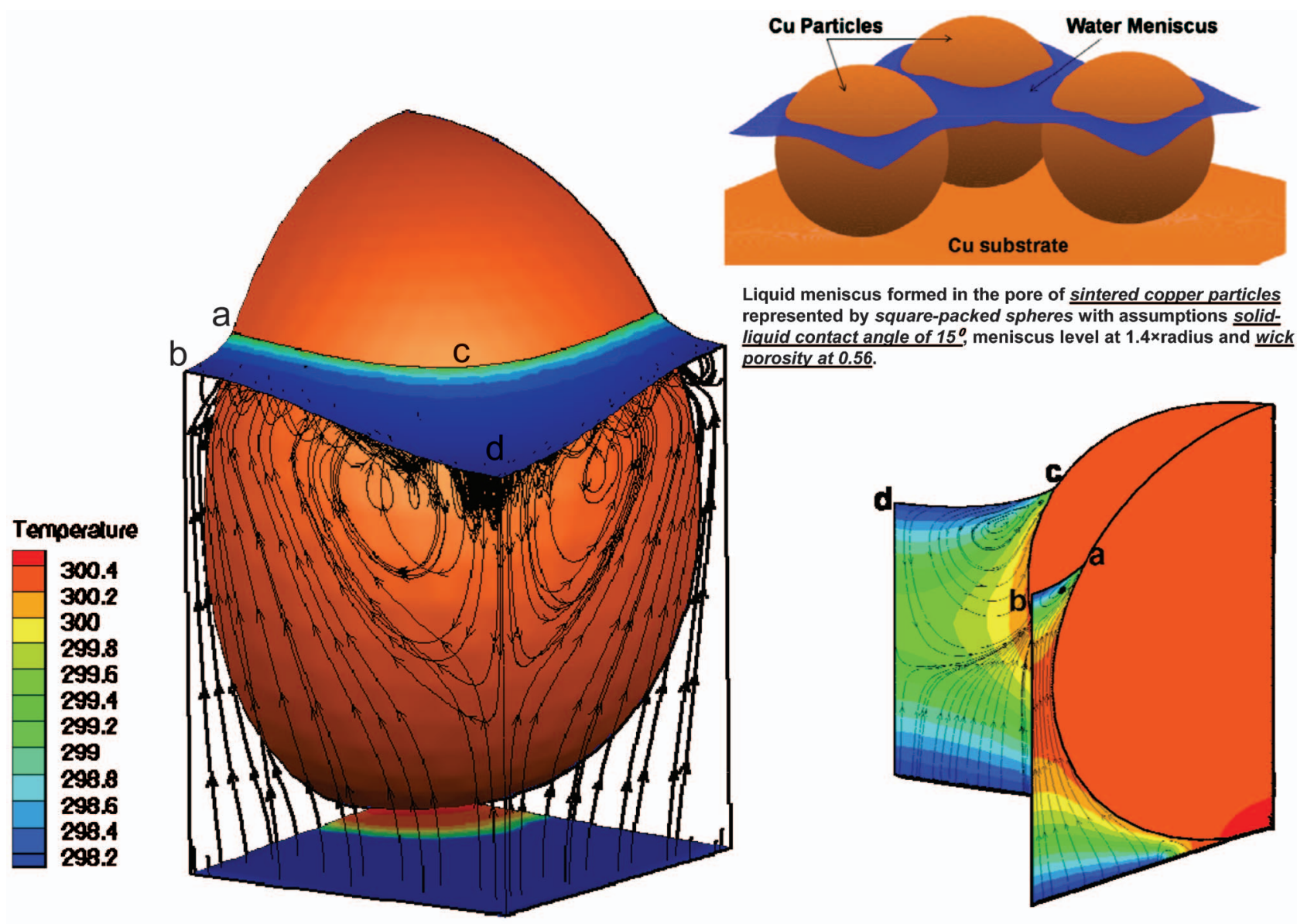

Liquid meniscus formed in the pore of sintered copper particles represented by square-packed spheres with assumptions solidliquid contact angle of $15^{\circ}$, meniscus level at $1.4 \times$ radius and wick porosity at 0.56 .

Complex-shaped toroidal vortex due to Marangoni convection observed in the wick pore during evaporation of water from sintered copper particles; temperature contours shown on the interface, liquid inlet and particle surface for solid wall temperature $=300.5 \mathrm{~K}$ and vapor temperature $=298 \mathrm{~K}$

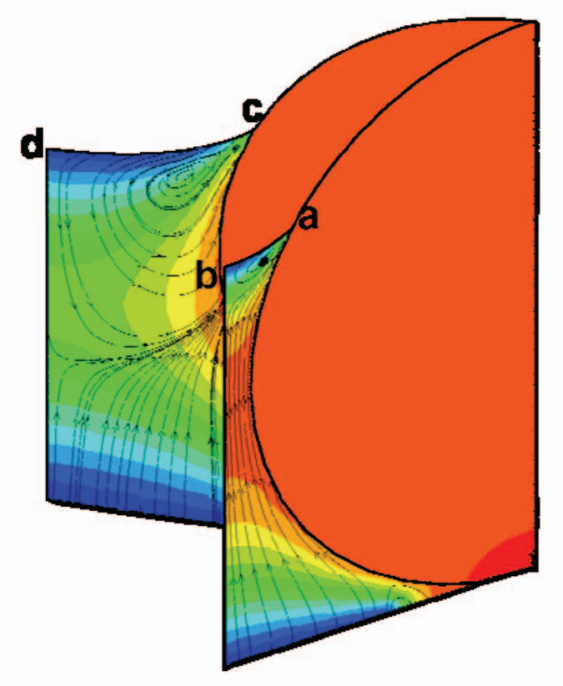

Marangoni vortices shown in the central (c-d) and narrow (a-b) planes in liquid region; vortex diameter is a maximum in the central plane and a minimum in the narrow plane.

\section{Marangoni Convection and Thin-film Evaporation in Microstructured Wicks for Heat Pipes Ram Ranjan, Jayathi Y. Murthy and Suresh V. Garimella NSF Cooling Technologies Research Center \\ School of Mechanical Engineering, Purdue University, West Lafayette, Indiana 47907-2088 USA}

An evaporating liquid meniscus is modeled under saturated vapor conditions in wick microstructures. The liquid-vapor interface shape is assumed to be static during evaporation. Liquid-vapor interface shapes in different wick geometries are obtained by solving the Young-Laplace equation using Surface Evolver. Mass, momentum and energy equations are solved numerically in the liquid domain. Evaporation at the interface is modeled using kinetic theory. Owing to nonisothermal evaporation from liquid-vapor interface, complex Marangoni convection vortices are observed below liquidvapor interface in the pores of sintered particle wicks. More than $80 \%$ of total evaporation heat transfer from the meniscus occurs from $20 \%$ of the total meniscus area, identified as the thin-film area. Marangoni convection has less than a $5 \%$ effect in enhancing evaporation from the liquid-vapor interface for superheats $<5 \mathrm{~K}$ (pertinent to heat pipes). 